\title{
Una propuesta de Anteproyecto de reforma de la Ley de la jurisdiccion contencioso-administrativa por la que se regula la conciliacion y el arbitraje intraprocesal
}

\author{
Alfonso Pérez Moreno \\ Catedrático de Derecho Administrativo \\ Universidad de Sevilla

\begin{abstract}
Texto definitivo de la propuesta que fue presentado al Ministerio de Justicia en 2017
\end{abstract}

\section{EXPOSICION DE MOTIVOS} \\ 1.- La tendencia favorable a la implantación de fórmulas alternativas a la vía \\ jurisdiccional para la solución de conflictos no ha alcanzado aun una realidad efec- \\ tiva en la materia jurídico-administrativa. Aunque el art. 107 de la Ley 30/92 de \\ Régimen Jurídico y Procedimiento Administrativo Común permitió sustituir los \\ recursos administrativos ordinarios por otros procedimientos de impugnación, re- \\ clamación, conciliación, mediación y arbitraje, aun no se ha realizado el desarrollo
} legislativo necesario.

Asimismo puede considerarse sin implantación el art. 77 de la Ley de la Jurisdicción Contencioso-Administrativa vigente sobre la conciliación dada la escasa aplicación del precepto debido a su limitada potencialidad.

El incesante incremento de los procesos contencioso-administrativos y la acelerada evolución de la complejidad de amplios sectores del ordenamiento jurídico acentúan la conveniencia de avanzar en la incorporación a la Ley de esta Jurisdicción de nuevos instrumentos de técnica jurídica más eficaces para agilizar los procesos como se está experimentando también en otros Estados.

2.- En la presente reforma se introduce en el art. 77 como posibles no sólo la conciliación sino también el arbitraje. Por medio de la ley y dentro de los límites constitucionales establecidos en los arts. 24.1, 106.1 y 117 de la Constitución se acogen dichas técnicas no sólo con el carácter extrajudicial con que las incorporó el referido art. 107 de la Ley 30/92, sino como posibles formas de terminación del proceso. 
Aunque se puedan desarrollar legalmente esos instrumentos sólo como alternativos a los recursos administrativos -y así se han regulado parcialmente en algunos casos a niveles autonómicos y estatal- en esta ley se prolonga su efecto como finalizadores del proceso, aunque siempre bajo el control de la potestad jurisdiccional exclusiva de los jueces y tribunales. Todos los límites constitucionales son respetados incluso en la institución arbitral. Siempre se ha encontrado en la imprescindible apertura y preeminencia de la vía judicial el impedimento para la aceptación del arbitraje en el Derecho Administrativo. En la fórmula que ahora aplica esta ley el arbitraje intraprocesal es un instrumento respetuoso con la Constitución y muy útil para aumentar la garantía jurisdiccional en el control de las actuaciones administrativas. Estos efectos los aspira a obtener la ley, de una parte, determinando las materias a las que es posible aplicar el arbitraje, y de otra, configurando los árbitros "ad hoc" caracterizados por su especialización y su experiencia.

3.- En cuanto a las materias a las que puedan aplicarse las fórmulas alternativas la ley las delimita con referencias genéricas que deberán interpretar los jueces y tribunales a los que, en todo caso, corresponderá la decisión en cada supuesto de la procedencia de su aplicación reconociéndoles tanto la facultad de denegarlas como la de avocar la competencia cuando el desarrollo del asunto presentara nuevas circunstancias que lo hicieran conveniente. Las referencias genéricas delimitadoras de las materias giran en torno a la determinación de conceptos fácticos legalmente indeterminados; concreción de magnitudes, parámetros o estándares de aplicación de la legislación sobre urbanismo, medio ambiente, ordenación del territorio y, en general, en todas las modalidades de planificación general o sectorial; fijación de la cuantía de indemnizaciones, justiprecios, compensaciones o rescates; interpretación de reglas sobre las prestaciones en las relaciones bilaterales; y cualquier otra que establezcan normas legales.

Las materias expresamente excluidas son las infracciones de derechos fundamentales; las que se refieran a determinación y ejercicio de potestades administrativas o funciones de autoridad; y las relativas al ejercicio de la potestad sancionadora salvo los casos en que procedan las terminaciones convencionales de los procedimientos.

4.- Los árbitros "ad hoc" que introduce esta ley como colaboradores de los órganos jurisdiccionales parten de la figura histórica de los Relatores que existieron en España hasta la Ley Orgánica del Poder Judicial, regulados por las Ordenanzas para todas las Audiencias de la Península e Islas adyacentes (Real Decreto de 19 de diciembre de 1835). Se introducen importantes innovaciones entre las que destacan las siguientes:

A) Pueden ser Relatores los funcionarios en situación de jubilados o excedentes procedentes de los Cuerpos de Magistrados, Catedráticos o Profesores Titulares de 
Derecho Administrativo, Abogados del Estado, Letrados de Comunidades Autónomas, Secretarios de Ayuntamiento, Letrados del Consejo de Estado y Abogados no ejercientes especializados en Derecho Administrativo.

B) Los Relatores serán seleccionados por concurso y estarán sometidos a una relación de inamovilidad otorgada anualmente.

C) Como colaboradores de los órganos jurisdiccionales contencioso-administrativos sus funciones pueden ser de Relatores ponentes o de Relatores árbitros bajo el control del órgano jurisdiccional que los requiera y designe mediante insaculación con participación de las partes litigantes.

A la regulación de los Relatores dedica esta Ley la Disposición Adicional.

5.- El procedimiento es especial integrado por los trámites necesarios para garantizar el consentimiento y participación de las partes y el control del órgano jurisdiccional tanto en el impulso de la colaboración del Relator como en la depuración de causas de nulidad.

6.- La Ley contiene una Disposición Transitoria sobre su posible aplicación a los procesos pendientes.

\section{Art. 1. Se modifica el art. 77 que quedará redactado en los siguientes términos:}

Art. 77.- Conciliación.

El párrafo 1 quedará redactado en los siguientes términos:

1. En los procedimientos en primera o única instancia, el Juez o Tribunal, de oficio o a solicitud de parte, una vez formuladas la demanda y la contestación, podrá someter a la consideración de las partes el reconocimiento de hechos o documentos, así como la posibilidad de alcanzar un acuerdo que ponga fin a la controversia, cuando el juicio se promueva sobre las materias susceptibles de arbitraje intraprocesal regulado en el artículo siguiente.

Art. 77 bis.- Arbitraje intraprocesal.

1.- En los procesos contenciosos-administrativos podrá aplicarse el arbitraje intraprocesal siguiendo el procedimiento especial del presente artículo siempre que versen sobre las siguientes materias:

a) Las susceptibles de transacción. 
b) La fijación de la cuantía de indemnizaciones, justiprecios, compensaciones o rescates.

c) La determinación de conceptos fácticos legalmente indeterminados.

d) La interpretación de las reglas sobre las prestaciones en las relaciones bilaterales.

e) La concreción de magnitudes, parámetros, estándares en la aplicación de la legislación sobre urbanismo, protección del medio ambiente, ordenación del territorio, y, en general, en todas las modalidades de planificación sectorial.

f) Las demás que se establezcan en normas legales.

Quedan en todo caso excluidas del procedimiento de arbitraje intraprocesal:

a) Infracciones de derechos fundamentales.

b) Reconocimiento, modificación o extinción de la titularidad o del ejercicio de potestades administrativas.

c) Control de las decisiones administrativas unilaterales sobre valoración directa del interés general.

d) Ejercicio de la potestad sancionadora cuando legalmente se permita la terminación convencional.

e) Ejercicio directo de funciones de autoridad.

2.- El procedimiento arbitral podrá iniciarse por petición de una o ambas partes o de oficio por decisión del Juez o de la Sala con competencia en primera o única instancia. Las Salas podrán asignar la competencia para resolver estos procedimientos a los Magistrados que la integren, sin perjuicio de poder avocarla en cualquier momento.

3.- Si el procedimiento lo iniciara el recurrente mediante interposición del recurso con o sin petición de medidas cautelares, el órgano jurisdiccional dará audiencia a la parte que no haya iniciado el procedimiento, por término de diez días para que alegue tanto sobre la procedencia del arbitraje como sobre las medidas cautelares que se hayan solicitado. Se exceptúa el caso de que el procedimiento se haya iniciado conjuntamente por ambas partes. Si en el curso de un proceso el órgano jurisdiccional hubiera planteado de oficio a las partes la propuesta de someter a arbitraje sus diferencias, les dará audiencia por término de cinco días. En todo caso, el órgano jurisdiccional actuante podrá citar a las partes a una comparecencia en término de tres días.

Si alguna de las partes se opusiera deberá continuar la tramitación del proceso ordinario en la fase en que se encuentre. 
4.- El órgano jurisdiccional dictará Auto en el que se apruebe la procedencia del arbitraje, se concreten los términos del conflicto, se nombre Relator árbitro mediante insaculación entre los homologados conforme a la Disposición Final de esta ley y se fije plazo para la emisión del laudo. Contra este Auto sólo se podrá interponer en el plazo de cinco días recurso de queja basado en vicios de nulidad por infracciones de normas de procedimiento determinantes de indefensión.

5.- El Relator árbitro colaborará con el órgano jurisdiccional durante los trámites de demanda y contestación a la demanda, si estuvieran pendientes, así como en la proposición y práctica de las pruebas, pudiendo comunicarse con los representantes y Abogados de las partes para aclaraciones e impulso de los trámites. Asimismo podrá proponer la adopción de diligencias para mejor proveer, que acordará el órgano jurisdiccional.

6.- Recibido el laudo el órgano jurisdiccional dictará Auto dando por terminado el procedimiento, si aquel no fuera manifiestamente contrario al ordenamiento jurídico ni lesivo del interés público o de terceros, y ordenará a las partes su cumplimiento en un plazo determinado. En todo caso, será aplicable el art. 113 de la Ley 29/98, reguladora de la Jurisdicción Contencioso-Administrativa.

7.- Contra dicho Auto se podrá interponer recurso de súplica ante el órgano jurisdiccional basado en vicios de nulidad, en el plazo de cinco días. Contra la desestimación del recurso de súplica podrá interponerse recurso de queja ante el Tribunal Supremo. Si el recurso fuera estimado, el órgano jurisdiccional sin más trámite que el que convenga para la subsanación de las indefensiones producidas, señalará día para dictar Sentencia, contra la que sólo podrá interponerse recurso de casación para la unificación de doctrina.

\section{Disposición Transitoria.-}

Los Jueces y Tribunales de lo Contencioso-Administrativo podrán aplicar, de oficio o de acuerdo con las partes, el procedimiento especial para la aplicación del arbitraje alternativo, en todos los procesos en que en la fecha de su entrada en vigor no exista señalamiento para dictar Sentencia. En estos supuestos, una vez designado Relator árbitro le será entregada copia de los autos para que sin más trámite dicte el laudo en el plazo que señale el órgano judicial. Si no se hubiera formulado la demanda se seguirá el procedimiento arbitral conforme al artículo 77 bis.

\section{Disposición Adicional.- Relatores.-}

1.- Para la colaboración con los órganos jurisdiccionales contencioso-administrativos en el procedimiento especial de arbitraje intraprocesal se crean los Relatores 
que serán seleccionados por concurso entre los funcionarios en situación de jubilados o excedentes procedentes de los Cuerpos de Magistrados, Catedráticos y Profesores Titulares de Derecho Administrativo, Abogados del Estado, Letrados de Comunidades Autónomas, Secretarios de Ayuntamientos, Letrados del Consejo de Estado y Abogados no ejercientes especializados en Derecho Administrativo.

2.- La Comisión para la resolución del concurso de designación de Relatores estará integrada por representantes del Consejo General del Poder Judicial y del Ministerio de Justicia. Los seleccionados quedarán a disposición de los órganos jurisdiccionales contencioso-administrativos que los designen por insaculación, en una situación de inamovilidad otorgada anualmente.

Sus retribuciones serán de un complemento equivalente al cien por cien de la pensión que perciban o les correspondiera percibir por su jubilación.

3.- En ningún caso se podrán compatibilizar las funciones de Relator con el ejercicio de la Abogacía.

4.- En los casos en que en el desarrollo del procedimiento especial de arbitraje intraprocesal el Relator árbitro elegido no terminara su función podrá mantener su colaboración con el órgano jurisdiccional como Relator ponente en el mismo proceso.

5.- Se autoriza al Ministerio de Justicia para el desarrollo reglamentario del estatuto de los Relatores. 